\title{
4-[2-(Trimethylsilyl)ethynyl]benzoates: Synthesis and evaluation for mesomorphic properties of some novel calamitic molecules ${ }^{\text {th }}$
}

\author{
H.T. Srinivasa ${ }^{\text {a, b }}$, S. HariPrasad ${ }^{\text {a, * }}$ \\ ${ }^{a}$ Department of Post Graduate Studies in Chemistry, Central College Campus, Palace Road, Bangalore University, Bangalore 560001, Karnataka, India \\ ${ }^{\mathrm{b}}$ Raman Research Institute, Sadashivanagar, Bangalore 560080, Karnataka, India
}

\section{A R T I C L E I N F O}

\section{Article history:}

Received 10 May 2014

Received in revised form

8 September 2014

Accepted 9 September 2014

Available online 15 October 2014

Keywords:

4-[2-(trimethylsilyl)ethynyl]benzoates

Organosilyl reagents

Liquid crystals

Calmitics

Smectic phases

\begin{abstract}
A B S T R A C T
A series of novel terminal trimethylsilylacetylene benzoate derivatives with various linking groups were synthesized using Friedel-Craft's O-acylation reaction. The chemical structures of the novel 4-[2-(trimethylsilyl)ethynyl]benzoates were confirmed by standard spectroscopic techniques. The compounds were investigated for their liquid crystalline properties employing polarised optical microscopy and differential scanning calorimetry. The esters $\mathbf{5 c}-\mathbf{5 f}, \mathbf{5 h}$ and $\mathbf{5 n}$ possessing three phenyl rings exhibited liquid crystalline property of $\mathrm{SmA} / \mathrm{SmC}$ phases with wide thermal range.
\end{abstract}

(c) 2014 Elsevier B.V. All rights reserved.

\section{Introduction}

Organosilicon chemistry covers a very broad field of research that ranges from synthetic and mechanistic organic chemistry [1-3], bio-organic silicon chemistry to application of organosilicon compounds in material science, encompassing all aspects of synthetic molecular, macromolecular, inorganic, co-ordination and physical chemistries [4,5].

In the early stages of liquid crystals research it was recognized that one end of the terminal substituent attached to the molecular core had to be a flexible aliphatic chain in order to dilute the central rigid organic core thereby inducing a relatively low melting point, or at least a melting point low enough for liquid crystalline property to exist [6].

Literature reports indicate terminal trimethylsilyl containing alkynyls with two phenyl rings and their respective metal acetylenes possess thermodynamically unstable mesophases. The instability is due to the sterically hindered much larger trimethylsilyl group on the terminal position of the molecule [7]. To rectify this problem, short/long siloxane units were incorporated to get stable, interesting mesophases, with electro-optic properties in low molar mass organosilicon liquid crystals [8-10]. The siloxane

\footnotetext{
* Dedicated to Prof. B. K. Sadashiva, RRI, Bangalore 560080, India.

* Corresponding author. Tel.: +91 8022961351; fax: +91 8022961331.

E-mail address: hariprasad@bub.ernet.in (S. HariPrasad).
}

based liquid crystal materials exhibited the attractive properties as a result of the flexibility of the siloxane swallow tail backbone. The flexibility of the siloxane also led to low viscosities and low glass transition temperatures [11].

In the skeleton of calamitic compounds, incorporation of a carbon-carbon triple bond in the terminal position or between two phenyl rings led to stable enantiotropic nematic phases [12,13]. The use of bulky siloxane group, at the expense of the smectic A (SmA) and nematic phases, which in most cases were eliminated, left the smectic $\mathrm{C}(\mathrm{SmC})$ phase as the sole liquid crystal phase. The inclusion of short, bulky siloxane terminal units markedly enhanced the stability of the SmC phase. This class of compounds showed by far the lowest viscosity leading to a class of novel materials which were excellent candidates for ferroelectric properties [14].

Based on our experience in the synthesis of organosilyl reagents and their applications [15-18], we envisaged that modification of siloxane into the terminal acetylenic trimethylsilyl group would result in rod-shaped compounds that could exhibit interesting liquid crystal properties giving rise to a new class of materials. To our knowledge, 4-[2-(trimethylsilyl)ethynyl]benzoic acid 2 [19] has not been used for the preparation of mesogenic materials [20].

In this report, for the first time, we describe the synthesis of 4[2-(trimethylsilyl)ethynyl]benzoic acid by Sonogashira coupling reaction and its conversion to the related benzoates $5 \mathbf{a}-\mathbf{o}$. These trimethylsilyl derived rod shaped compounds have been specifically synthesized to favour and attain liquid crystalline property. 


\section{Results and discussions}

Trimethylsilylacetylene was subjected to Sonogashira coupling with 4-iodobenzoic acid (1) in presence of $\mathrm{PdCl}_{2} / \mathrm{CuI} / \mathrm{PPh}_{3} / \mathrm{Et}_{3} \mathrm{~N}$ to obtain 2. The substrate $\mathbf{2}$ was then converted into the corresponding acid chloride $\mathbf{3}$ using oxalyl chloride at room temperature and subjected to Friedel-Crafts O-acylation reaction with phenols $\mathbf{4 a}-\mathbf{o}[21-25]$ in pyridine base [26] to obtain the novel benzoates 5a-o possessing three phenyl rings and a trimethylsilyl group in the terminal position. The synthetic strategy is outlined in Scheme 1.

The chemical structures of the 4-[2-(trimethylsilyl)ethynyl] benzoates $\mathbf{5 a}-\mathbf{o}$ were confirmed by standard spectroscopic techniques.

\section{Thermal and liquid crystal properties}

The compounds $\mathbf{5 a}-\mathbf{o}$ were evaluated for liquid crystalline properties using the combination of polarised optical microscopy (POM) and differential scanning calorimetry (DSC). The trimethylsilyl derived rod-shaped esters with different substituents on lateral and peripheral positions of the aromatic core with various linking groups are shown in Table 1.

The transition temperatures and the associated enthalpy values for $\mathbf{5 a}-\mathbf{o}$ are summarized in Table 2 .

To verify the liquid crystalline textures, in general, the samples were sandwiched between untreated glass plates and a cover slip and heated up to its isotropic point and then slowly cooled from the isotropic liquid and observed under POM.

Compounds 5a and $\mathbf{5 b}$ with biphenyl core were found to be nonliquid crystalline. Compounds $\mathbf{5 c}$ and $\mathbf{5 d}$ showed stable enantiotropic SmA phase. In addition to the SmA phase, compound 5d showed monotropic SmC phase. During heating, 5d transformed from crystal to SmA phase and then to isotropic phase, but during cooling, the compound 5d transformed from isotropic phase to SmA phase and SmC phase and the crystallised. The SmC phase was identified by POM and DSC. Typical fan shaped texture and fan shaped striped texture were observed for the SmA and SmC phases. The textures are re-produced in Fig. 1.

Compounds 5a-5d have biphenyl moiety in the central rigid part with polar cyano-, methylester and dodecyloxy-groups at terminal positions. The compounds were found to possess relatively higher transition temperatures compared to other ester compounds.

The three phenyl rings possessing compounds $\mathbf{5 e}$ and $\mathbf{5 f}$ have short alkoxy chains and polar cyano groups respectively with ester linkage. Both the compounds favoured liquid crystalline property exhibiting SmA phases. The POM textures are depicted in Fig. 1. Interestingly, introduction of polar nitrile group at the terminal
Table 1

General chemical structures of 4-[2-(trimethylsilyl)ethynyl]benzoic acid derivatives of $\mathbf{5 a}-\mathbf{o}$.

\begin{tabular}{lllll}
\hline Compound & $\mathrm{X}$ & $\mathrm{Y}$ & $\mathrm{Z}$ & $\mathrm{R}$ \\
\hline $\mathbf{5 a}$ & None & $\mathrm{H}$ & $\mathrm{H}$ & $\mathrm{H}$ \\
$\mathbf{5 b}$ & None & $\mathrm{H}$ & $\mathrm{H}$ & $\mathrm{CN}$ \\
$\mathbf{5 c}$ & None & $\mathrm{H}$ & $\mathrm{H}$ & $\mathrm{COO}-\mathrm{CH}_{3}$ \\
$\mathbf{5 d}$ & None & $\mathrm{H}$ & $\mathrm{H}$ & $\mathrm{OC}_{14} \mathrm{H}_{29}$ \\
$\mathbf{5 e}$ & $-\mathrm{COO}-$ & $\mathrm{H}$ & $\mathrm{H}$ & $\mathrm{OC}_{5} \mathrm{H}_{11}$ \\
$\mathbf{5 f}$ & $-\mathrm{COO}-$ & $\mathrm{H}$ & $\mathrm{H}$ & $\mathrm{CN}^{-}$ \\
$\mathbf{5 g}$ & $-\mathrm{COO}-$ & $\mathrm{H}$ & $\mathrm{CH}$ & $\mathrm{NO}_{2}$ \\
$\mathbf{5 h}$ & $-\mathrm{COO}-$ & $\mathrm{H}$ & $\mathrm{H}$ & $\mathrm{O}\left(\mathrm{CH}_{2}\right)_{2} \mathrm{CH}\left(\mathrm{CH}_{3}\right)\left(\mathrm{CH}_{2}\right)_{3} \mathrm{CH}\left(\mathrm{CH}_{3}\right)_{2}$ \\
$\mathbf{5 i}$ & $-\mathrm{COO}-$ & $\mathrm{H}$ & $\mathrm{H}$ & $\mathrm{COO}_{-} \mathrm{CH}\left(\mathrm{CH}_{3}\right) \mathrm{C}_{6} \mathrm{H}_{13}$ \\
$\mathbf{5 j}$ & $-\mathrm{COO}-$ & $\mathrm{H}$ & $\mathrm{H}$ & $\mathrm{OC}_{16} \mathrm{H}_{33}$ \\
$\mathbf{5 k}$ & $-\mathrm{COO}-$ & $\mathrm{CH}$ & $\mathrm{H}$ & $\mathrm{OC}_{18} \mathrm{H}_{37}$ \\
$\mathbf{5 l}$ & $-\mathrm{OCH}-$ & $\mathrm{H}$ & $\mathrm{H}$ & $\mathrm{H}$ \\
$\mathbf{5 m}$ & $-\mathrm{COOCH}-$ & $\mathrm{H}$ & $\mathrm{H}$ & $\mathrm{H}$ \\
$\mathbf{5 n}$ & $-\mathrm{N}=\mathrm{N}-$ & $\mathrm{H}$ & $\mathrm{H}$ & $\mathrm{NO}_{2}$ \\
$\mathbf{5 o}$ & $-\mathrm{N}=\mathrm{N}-$ & $\mathrm{H}$ & $\mathrm{H}$ & $\mathrm{C}_{5} \mathrm{H}_{11}$ \\
\hline
\end{tabular}

Table 2

Transition temperatures $\left({ }^{\circ} \mathrm{C}\right)$ and associated enthalpy values $\left(\mathrm{kJ} \mathrm{mol}^{-1}\right)$ for compounds $\mathbf{5 a}-\mathbf{o}$.

\begin{tabular}{|c|c|c|}
\hline Compound & Heating scan & Cooling scan \\
\hline $5 \mathbf{a}$ & Cr 175.1(127.5) Iso & Iso $144.1(83.3) \mathrm{Cr}$ \\
\hline $5 \mathbf{b}$ & Cr 200.1(72.7) Iso & Iso $162.1(76.2) \mathrm{Cr}$ \\
\hline \multirow[t]{2}{*}{$5 c$} & Cr 204.5(33.6) & Iso $247.1(3.3)$ \\
\hline & SmA 251.2(3.8) Iso & SmA $196.9(31.9) \mathrm{Cr}$ \\
\hline \multirow[t]{3}{*}{$5 d$} & Cr 133.3(81.6) & Iso $166.4(11.7)$ \\
\hline & SmA 168.5(11.9) Iso & SmA 128.8(7.7) \\
\hline & & $\mathrm{SmC} 110.2(53.5) \mathrm{Cr}$ \\
\hline \multirow[t]{2}{*}{$5 e$} & Cr 137.4(41.8) Iso & Iso $136.0(6.9)$ \\
\hline & & $\mathrm{SmA} 124.8(38) \mathrm{Cr}$ \\
\hline \multirow[t]{2}{*}{$5 f$} & Cr 156.3(66.4) & Iso $161.1(4.0)$ \\
\hline & SmA 162.1(4.1) Iso & $\mathrm{SmA} 107.4(67.9) \mathrm{Cr}$ \\
\hline $5 g$ & Cr $143.3(60.22)$ Iso & Iso $105.3(53.1) \mathrm{Cr}$ \\
\hline \multirow[t]{2}{*}{$5 h$} & Cr 100.2(42.1) Iso & Iso $86.6(6.8)$ \\
\hline & & $\mathrm{SmA} 77.2(43.4) \mathrm{Cr}$ \\
\hline $5 \mathbf{i}$ & Cr 81.5(45.1) Iso & Iso $47.4(18.6) \mathrm{Cr}$ \\
\hline $5 \mathbf{j}$ & Cr 110(76.9) Iso & Iso $102.1(56.4) \mathrm{Cr}$ \\
\hline 5k & Cr 95.5(71.6) Iso & Iso $75(54.4) \mathrm{Cr}$ \\
\hline 51 & Cr 141.5(103.1) Iso & Iso $116.5(95.) \mathrm{Cr}$ \\
\hline $5 \mathrm{~m}$ & Cr 93.3(68.9) Iso & Iso $25.5(24.7) \mathrm{Cr}$ \\
\hline \multirow[t]{2}{*}{$5 n$} & Cr 143.2(59.6) & Iso $191.7(5.4)$ \\
\hline & SmA 192.7(5.4) Iso & SmA 94.9(36.8) Cr \\
\hline 50 & Cr 142.1(68.2) Iso & Iso $135.1(64.4) \mathrm{Cr}$ \\
\hline
\end{tabular}

$\mathrm{Cr}=$ Crystal; $\mathrm{SmA}=$ Smectic A phase; $\mathrm{N}=$ Nematic phase; $\mathrm{g}=$ Glassy phase, while cooling crystallization is not observed.

position stabilized the mesophase in compound $\mathbf{5 f}$. The representive DSC scan of $\mathbf{5 d}, \mathbf{5 f}$, and $\mathbf{5 n}$ is shown in Fig. 2. The SmC phase is eliminated in $\mathbf{5 e}$ and $\mathbf{5 f}$ compounds. This may be due to the reduction of flexibility of the terminal chain (Fig. 3).

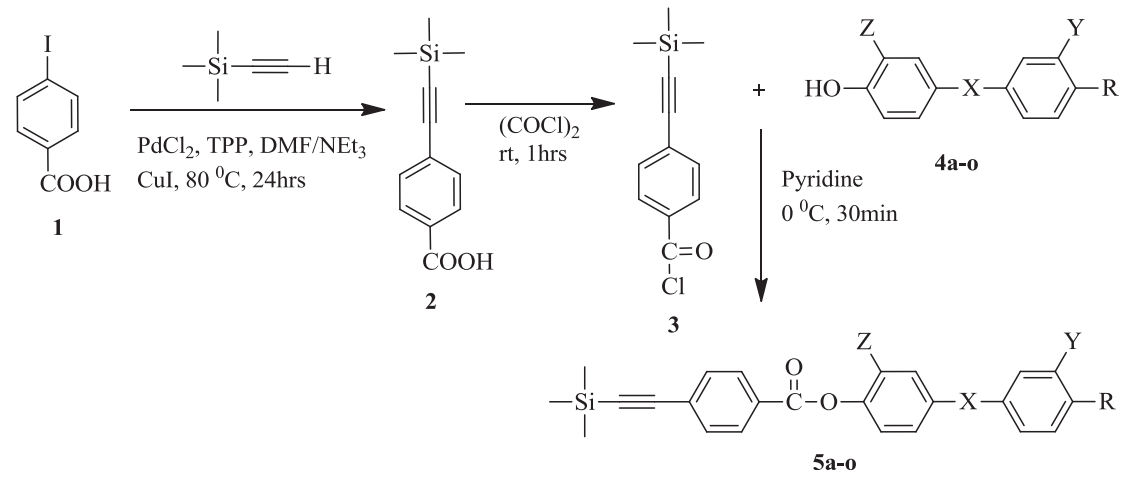

Scheme 1. Synthesis of 4-[2-(Trimethylsilyl)ethynyl] benzoates $\mathbf{5 a - o . ~}$ 

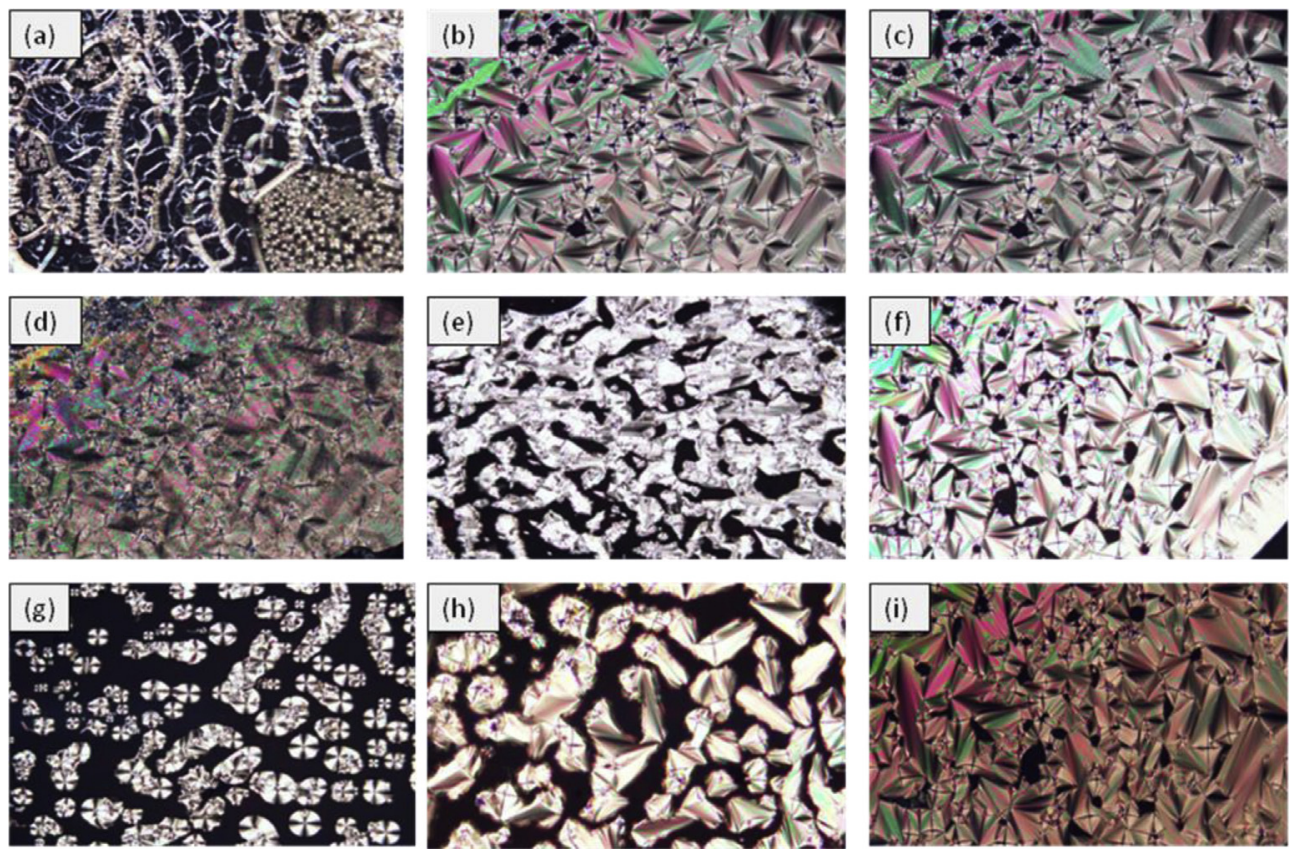

Fig. 1. Optical textures of (a) Smectic A phase of $\mathbf{5} \mathbf{c}$ on heating cycle at $215^{\circ} \mathrm{C}$, (b) Smectic A phase of $\mathbf{5 d}$ on cooling scan at $1400^{\circ} \mathrm{C}$ (c) Focal-conic striped texture for Smectic $\mathrm{C}$ phase of $5 \mathbf{d}$ on cooling cycle at $125^{\circ} \mathrm{C}$, (d) Crystalline phase of $5 \mathbf{d}$ on cooling cycle at $105^{\circ} \mathrm{C}$. (e) SmA phase of $5 \mathrm{e}$ on cooling cycle at $130^{\circ} \mathrm{C}$, (f) SmA phase of $\mathbf{5 f}$ on cooling cycle at $150{ }^{\circ} \mathrm{C}$, (g) SmA phase of $\mathbf{5 h}$ on cooling cycle at $80^{\circ} \mathrm{C}$. (h) SmA phase of $\mathbf{5 n}$ on early stage of cooling cycle at $185^{\circ} \mathrm{C}$. (i) $\mathrm{SmA}$ phase of $5 \mathbf{n}$ complete grown texture on cooling cycle at $100{ }^{\circ} \mathrm{C}$.

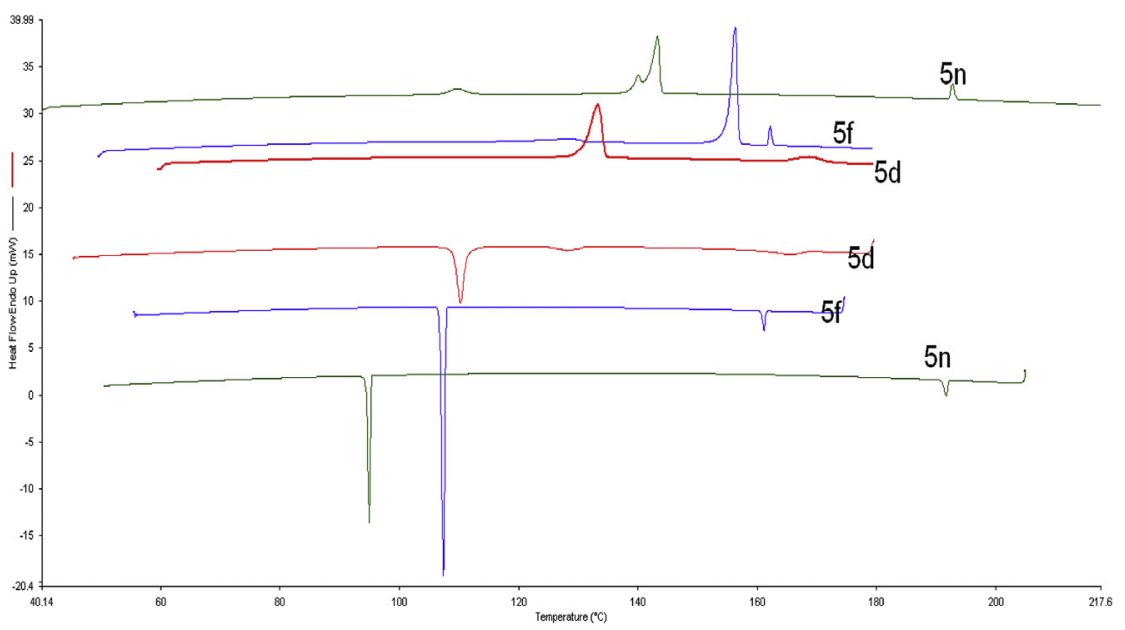

Fig. 2. DSC thermogram (exothermic/endothermic cycles) of $\mathbf{5 d}, \mathbf{5 f}$ and $\mathbf{5 n}$.

In the compounds $\mathbf{5 g}$ and $\mathbf{5 h}$ which have three phenyl rings with ester linkage, lateral methyl group, terminal polar nitro-group and branched alkyl chains respectively, significant changes were found to have occured. The compound $\mathbf{5 g}$ did not show any phase.

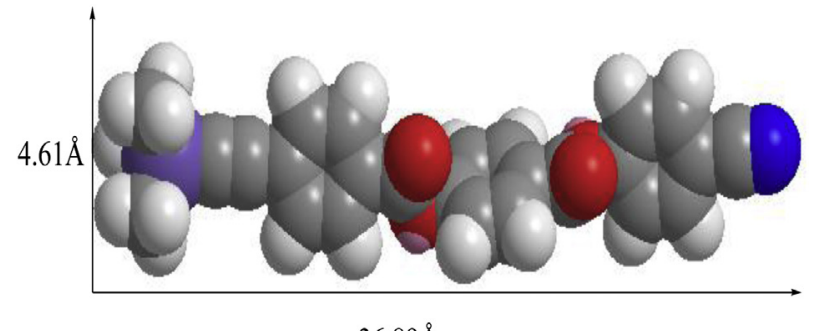

$36.89 \AA$

Fig. 3. Average length/breadth showing energy optimized space filled model of $\mathbf{5 f}$.
However, compound $\mathbf{5 h}$ showed only monotropic SmA phase as shown in Fig. 1.

The DSC and POM results show that the compounds $\mathbf{5 d}, \mathbf{5 e}$ and 5h forms thermodynamically unstable monotropic liquid crystalline SmA phase. The monotropic liquid crystalline phases were observed only in the cooling scan. This behaviour possesses thermodynamic metastability throughout the entire temperature and experimental process, and in which the crystallization process is bypassed by under cooling due to the kinetically controlled nucleation process [27]. In addition, the monotropic transition also causes due to competition in entropy contributions of the core and the chain, thermal dynamics, structural and its environmental changes during the phase transition process of the alkyl chains [28,29].

The compounds $\mathbf{5 i}-\mathbf{5 k}$ having chiral/short/long alkyl chains respectively, did not show any liquid crystalline phase. Introduction of long alkoxy chain in the terminal position of the molecule had a 
dramatic effect on its mesophase behaviour, indicating that mesophase is completely eliminated and may be due to flexibility of the saturated chain.

In $\mathbf{5 1}$ and $\mathbf{5 m}$ with benzyl linking group, the absence of terminal substitutions also led to complete elimination of liquid crystalline property.

Compounds $\mathbf{5 n}$ and $\mathbf{5 0}$ have a central azo-linkage with highly polar nitro group and pentyl-chain at the terminal end of the molecules respectively. Significant changes were observed in mesophase and transition properties. The terminal polar nitro group derivative $\mathbf{5 n}$ favoured the liquid crystalline property exhibiting SmA phase (Fig. 1). However, 50 possessing alkyl chain with central azo-linkage did not favour liquid crystalline property.

It was observed that the liquid crystal property was reduced when the chain length increased due to the disturbance of the packing layers. Hence only shorter chain compounds exhibited liquid crystalline property. In general, we observe that compounds having three phenyl rings favour liquid crystallinity and exhibit SmA mesophase.

$X$-ray studies

The trimethylsilylethynylbenzoate $\mathbf{5 f}$ was examined from different dihedral angles using ChemDraw. The energy minimized structure shows the calculated average length of molecule to be 36.89 Å with breadth 4.61 Å respectively.

In order to reveal the mesophase structure, X-ray diffraction experiments were carried out using un-oriented sample at liquid crystalline state while cooling from the isotropic phase for $\mathbf{5 f}$ and $\mathbf{5 n}$ as shown in Fig. 4. In the small angle region of $\mathbf{5 f}$, a small sharp peak was observed at $36.97 \AA$, and in the wide-angle region, a diffuse reflection appeared at $4.75 \AA$ A. This corresponds to the liquidlike order of the aliphatic chain. According to theoretical and experimental data with local molecular structure and diffraction pattern, the features fit into the rod-like molecule and the layers stack one beside the other to form themselves in packed layers of the SmA phase.

\section{Photophysical properties}

Photophysical properties of $\mathbf{5 a}-\mathbf{o}$ were carried out using ultraviolet-visible spectroscopy. The measurements were performed in dilute $\mathrm{CH}_{2} \mathrm{Cl}_{2}$ solutions ranging between 5 and $10 \mathrm{mmol} / \mathrm{L}$. The respective electronic transition data are given in Table 3.

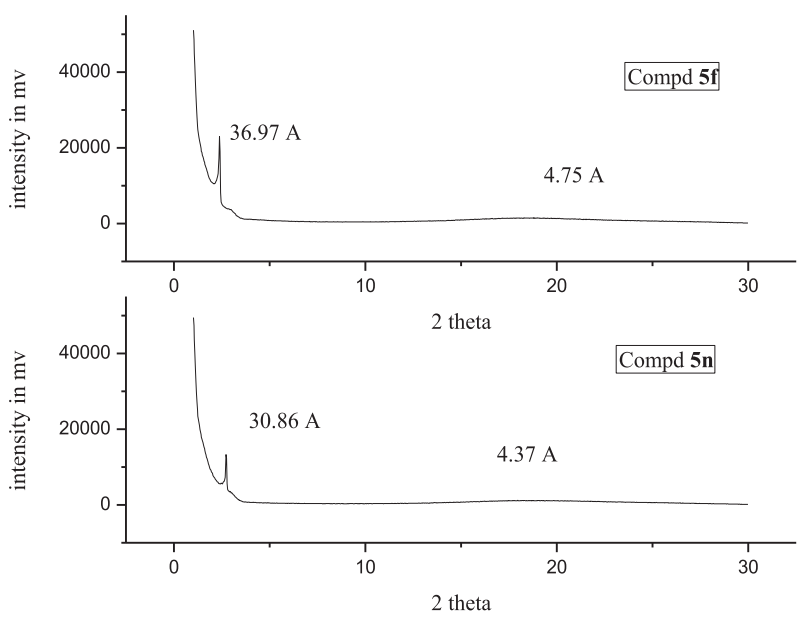

Fig. 4. X-ray diffraction pattern of $\mathbf{5 f}$ and $\mathbf{5 n}$ and at $140{ }^{\circ} \mathrm{C}$ and $160{ }^{\circ} \mathrm{C}$ respectively on cooling scan from isotropic state.
Table 3

Photophysical data of trimethylsilyl benzoate derivatives $\mathbf{5 a}-\mathbf{o}$.

\begin{tabular}{ll}
\hline Compound & Absorption $\left(\lambda_{\max }\right.$ in $\left.\mathrm{nm}\right)$ \\
\hline $\mathbf{5 a}$ & $256,288,292$ \\
$\mathbf{5 b}$ & $283,297,301$ \\
$\mathbf{5 c}$ & $222,282,289$ \\
$\mathbf{5 d}$ & $215,222,280$ \\
$\mathbf{5 e}$ & $278,328,382$ \\
$\mathbf{5 f}$ & $214,222,276$ \\
$\mathbf{5 g}$ & $220,277,282$ \\
$\mathbf{5 h}$ & $276,293,394$ \\
$\mathbf{5 i}$ & $215,276,366$ \\
$\mathbf{5 j}$ & $215,276,359$ \\
$\mathbf{5 k}$ & $216,232,274$ \\
$\mathbf{5 1}$ & $277,329,384$ \\
$\mathbf{5 m}$ & $220,233,354$ \\
$\mathbf{5 n}$ & $280,328,381$ \\
$\mathbf{5 o}$ & $217,282,337$ \\
\hline
\end{tabular}

Fig. 5 gives the representative UV absorption spectra of $\mathbf{5 e}, \mathbf{5 1}$ and $\mathbf{5 n}$. The representative compounds show an absorption band around $280 \mathrm{~nm}$ attributed to the $\pi-\pi^{*}$ electronic transition of the phenylene ring and low-intensity $n-\pi^{*}$ transition at $328-380 \mathrm{~nm}$ due to phenyl ring with ester linkage.

Compared to aromatic $\pi-\pi^{*}$ electronic transition, the red shift of the UV absorption band indicates an improved conjugation, due to the presence of ester linkage together with the phenyl ring leading to $\pi-\pi^{*}$ conjugation unit into the rigid core. These studies showed that the trimethylsilyl group did not take part in any role of UV absorption phenomena.

Thermal stability of $\mathbf{5 b}, \mathbf{5 j}$ and $\mathbf{5 o}$ was determined using thermogravimetric analysis (TGA). The corresponding plots are shown in Fig. 6. All the compounds were thermally stable up to approximately $250{ }^{\circ} \mathrm{C}$. Further, TGA results showed that $100 \%$ weight loss occurred between 250 and $400{ }^{\circ} \mathrm{C}$. In case of $\mathbf{5 0}$ decomposition occurred in two stages, which indicated that the azo linkage is comparatively more stable than the ester linkage.

\section{Conclusions}

The synthesis of fifteen benzoates possessing three phenyl ring containing arylalkynylsilyl and various lateral and terminal polar/ normal/branched substituent groups is reported. The POM and DSC studies indicate that all biphenyls with short chains exhibit Smectic phases. The liquid crystal property was reduced/eliminated when chain length increased. We reason this due to the packing layers

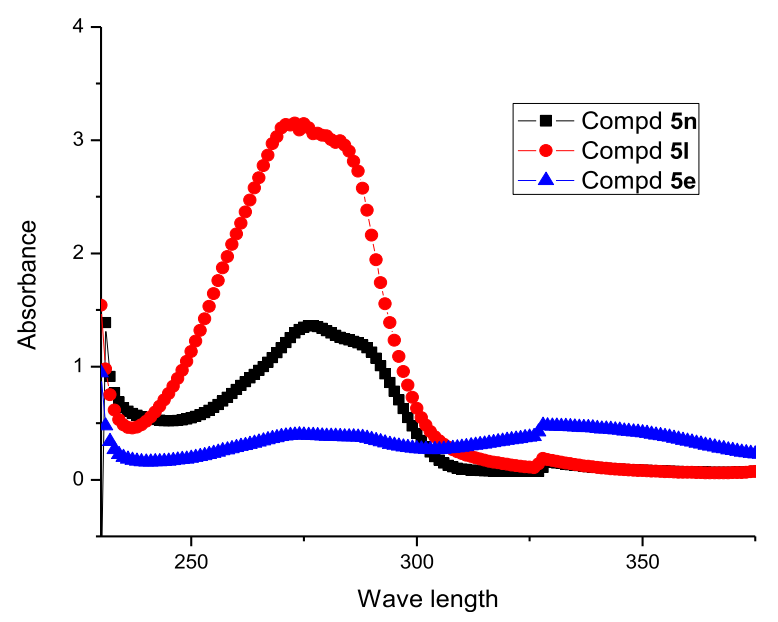

Fig. 5. UV/visible absorption spectra of $\mathbf{5 e}, \mathbf{5 1}$ and $\mathbf{5 n}$. 


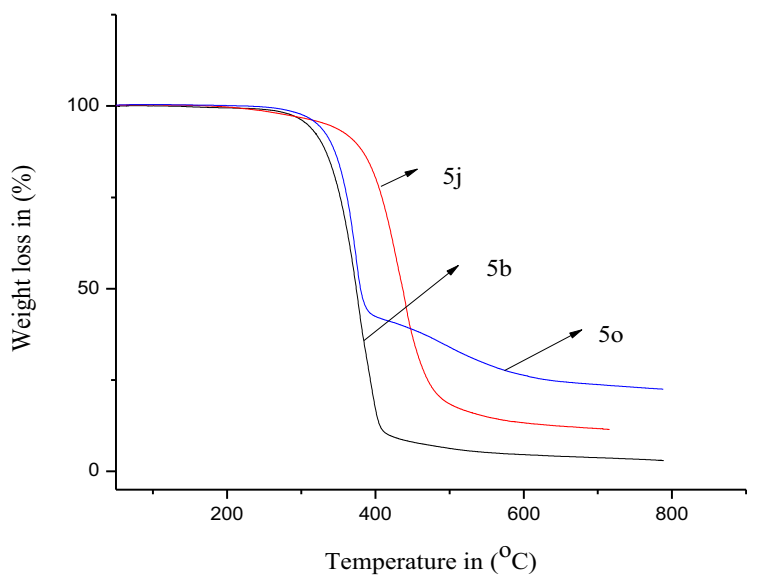

Fig. 6. Thermogravimetric analysis traces of $\mathbf{5 b}, \mathbf{5 j}$ and $\mathbf{5 0}$.

which has been significantly disturbed. Only biphenyl derivatives with short/long alkyl chain favour liquid crystalline property. Compounds possessing three phenyl rings with ester linkage and terminal long alkyl chains did not favour liquid crystalline property.

\section{Experimental}

\section{Materials and characterization}

All chemicals were purchased from Sigma-Aldrich and Merck and used as received. Solvents were distilled and dried prior to the reactions. All the reactions were monitored by thin layer chromatography using silica gel pre-coated on aluminium sheets with 1:4 ratio ethyl acetate and petroleum benzene $\left(60-80{ }^{\circ} \mathrm{C}\right.$ fraction) as mobile phase. The final compounds were purified by column chromatography on Acme make silica gel of 60-120 mesh size. The chemical structures were confirmed by ${ }^{1} \mathrm{H}$ NMR spectroscopy (Bruker Biospin $500 \mathrm{MHz}$ spectrometer). The chemical shifts are relative to $\mathrm{CHCl}_{3}\left(\delta 7.27 \mathrm{ppm}\right.$, singlet) for compounds with $-\mathrm{SiMe}_{3}$ group. ${ }^{13} \mathrm{C}$ NMR spectra was obtained (Bruker Biospin $125 \mathrm{MHz}$ spectrometer) using $\mathrm{CDCl}_{3}$ as a solvent and internal reference $(\delta$ $77.23 \mathrm{ppm}$, triplet). FTIR spectra were obtained using Shimadzu FTIR-8400 spectrometer. The purities of the final products were established by elemental analysis performed on Carlo-Erba 1106 analyzer. The thermal behaviour was investigated by Differential Scanning Calorimetry (DSC) using a Perkin-Elmer, Model Pyris 1 calibrated using indium and zinc standards. The phase characterization and observation of liquid crystal textures were performed by polarized optical microscope (POM) BX51 Olympus make equipped with a Mettler FP82HT hot stage and Mettler FP90 central processor. Thermal stability was established by Perkin Elmer TGA4000 analyser. The heating profile in all cases was a heating segment rate of $10{ }^{\circ} \mathrm{C} \mathrm{min}^{-1}$. Electrospray ionization mass spectrometry (ESI-MS) was carried out using Bruker Daltonics Esquire3000 instrument. X-ray diffraction studies were performed on nonoriented samples filled using Lindeman capillary, with a diameter of $1.0 \mathrm{~mm}$ using $\mathrm{Cu}-\mathrm{K} \alpha(0.154 \mathrm{~nm})$ radiation from a rotating anode $\mathrm{X}$-ray generator (Rigaku Ultrax-18) operating at $50 \mathrm{kV}$ and $80 \mathrm{~mA}$. Two-dimensional detector Image Plate from Mar Research was used for the collection of scattered radiation.

\section{Synthetic procedure for compound 2 [19]}

To a solution of 4-iodobenzoic acid ( $2.0 \mathrm{~g}, 1.0 \mathrm{mmol})$, copper (I) iodide $(1.7 \mathrm{~g}, 1.13 \mathrm{mmol})$, palladium chloride $(0.02 \mathrm{~g}, 0.15 \mathrm{mmol})$ and triphenylphosphine $(2.1 \mathrm{~g}, 1.0 \mathrm{mmol})$ in triethylamine $(7 \mathrm{ml})$, was added ethynyltrimethylsilane $(1.2 \mathrm{~g}, 1.5 \mathrm{mmol})$ dropwise over $30 \mathrm{~min}$. The resulting reaction mixture was then refluxed at $80^{\circ} \mathrm{C}$ for $24 \mathrm{~h}$ under an atmosphere of argon and monitored by TLC. After the completion of reaction, as indicated by the complete disappearance of starting material on TLC, the mixture was cooled and filtered through a Buchner funnel. The volatile solvents were removed under reduced pressure. The resulting crude light brown coloured material was extracted into ether, washed with brine solution, dried over anhydrous sodium sulphate, and concentrated. Finally the silylated product was purified by column chromatography on silica gel with $3 \%$ ethyl acetate in hexane as an eluent yielding $86 \%$ of pure 4 -[2-(trimethylsilyl)ethynyl]benzoic acid (2). Off white solid, 1.53 g; IR: 2953, 2156, 1681, 1604, 1454, 1377, 1251, $858 \mathrm{~cm}^{-1} ;{ }^{1} \mathrm{H}$ NMR $\left(500 \mathrm{MHz}, \mathrm{CDCl}_{3}\right): 8.0(\mathrm{~d}, J=8.6,2 \mathrm{H}, \mathrm{Ar}-\mathrm{H}), 7.6$ $(\mathrm{d}, J=8.4,2 \mathrm{H}, \mathrm{Ar}-\mathrm{H}), 0.27(\mathrm{~s}, 9 \mathrm{H})$.

\section{Friedel-Crafts O-acylation for the synthesis of compounds $\mathbf{5 a - 0}$}

A mixture of 4-[2-(trimethylsilyl)ethynyl]benzoyl chloride 3 $(0.100 \mathrm{~g}, 1.5 \mathrm{mmol}$ ) and $1 \mathrm{mmol}$ quantity of phenol each $\mathbf{4 a}-\mathbf{0}$ was stirred in dry pyridine $(5 \mathrm{ml})$ in an ice bath under inert atmosphere for $30 \mathrm{~min}$. The reaction mixture was allowed to attain room temperature. After the completion of the reaction, the reaction mass was poured into ice cold dilute hydrochloric acid, and extracted with DCM $(2 \times 25 \mathrm{ml})$. The organic layer was washed with saturated brine solution and dried over anhydrous sodium sulphate. The crude products obtained were purified by column chromatography using ethyl acetate:petroleum ether (2:8) as an eluent followed by recrystallization in hexane $\left(60-80{ }^{\circ} \mathrm{C}\right)$. The quantity (in grams) and percentage yields and of all final products are reported in the subsequent experimental section.

\section{1-[1'-biphenyl-4-yl \{4-(trimethylsilyl)\}ethynyl]benzoate (5a)}

1-[1'-Biphenyl-4-yl \{4-(trimethylsilyl)\}ethynyl]benzoate (5a): off white solid, 0.125 g, 80\%; IR: 2924, 2852, 2160, 1730, 1573, 1454, 1377, 1246, $840 \mathrm{~cm}^{-1}$; ${ }^{1} \mathrm{H}$ NMR (500 MHz, $\mathrm{CDCl}_{3}$ ): 8.13 (d, $2 \mathrm{H}$, $J=8.4 \mathrm{~Hz}, \mathrm{Ar}-\mathrm{H}), 7.61(\mathrm{~d}, J=8.6 \mathrm{~Hz}, 6 \mathrm{H}, \mathrm{Ar}-\mathrm{H}), 7.24(\mathrm{~m}, 5 \mathrm{H}, \mathrm{Ar}-\mathrm{H})$, $0.31\left(\mathrm{~s}, 9 \mathrm{H},-\mathrm{Si}\left(\mathrm{CH}_{3}\right)_{3}\right)$; Elemental analysis $\mathrm{C}_{24} \mathrm{H}_{22} \mathrm{O}_{2}$ Si requires $\mathrm{C}$, 77.80; H, 5.98; found C, 77.64; H, 6.05 .

\section{4'-Cyano-[1,1'-\{biphenyl-4-yl 4-(trimethylsilyl)\}ethynyl]benzoate} (5b)

4'-Cyano-[1,1'-\{biphenyl-4-yl 4-(trimethylsilyl)\}ethynyl]benzoate (5b) off white solid, $0.121 \mathrm{~g}, 71 \%$; IR: 2924, 2852, 2227, 1734, 1456, 1267, 1070, $844 \mathrm{~cm}^{-}$; ${ }^{1} \mathrm{H}$ NMR: 8.13 (d, $\left.2 \mathrm{H}, J=8.4 \mathrm{~Hz}, \mathrm{Ar}-\mathrm{H}\right)$, 7.74-7.56 (m, 8H, Ar-H), 7.35 (d, $2 \mathrm{H}, J=8.3 \mathrm{~Hz}, \mathrm{Ar}-\mathrm{H}), 0.30$ (s, 9H, $\left.-\mathrm{Si}\left(\mathrm{CH}_{3}\right)_{3}\right) ;{ }^{13} \mathrm{C}$ NMR $\left(100 \mathrm{MHz}, \mathrm{CDCl}_{3}\right): 164.5,151.3,144.7,137$, 132.6, 132.1, 130, 128.7, 128.4, 127.7, 122.4, 0.0; Elemental analysis $\mathrm{C}_{25} \mathrm{H}_{21} \mathrm{NO}_{2} \mathrm{Si}$ requires $\mathrm{C}, 75.92 ; \mathrm{H}, 5.35 ; \mathrm{N}, 3.54$; found $\mathrm{C}, 75.97 ; \mathrm{H}$, $5.12 ; \mathrm{N}, 3.49$.

Methyl-4'-[\{4-(trimethylsilyl)ethynyl-benzoyloxy\}-1,1'-biphenyl]-4carboxylate (5c)

Methyl-4'-[\{4-(trimethylsilyl)ethynyl-benzoyloxy\}-1,1'biphenyl]-4-carboxylate (5c) off white solid, 0.123 g, 68\%; IR: 2924, 2854, 2160, 1728, 1456, 1284, 1076, $839 \mathrm{~cm}^{-1}$; ${ }^{1} \mathrm{H}$ NMR: 8.12 (dd, 4H, $J=8.4 \mathrm{~Hz}, \mathrm{Ar}-\mathrm{H}), 7.63-7.55(\mathrm{~m}, 6 \mathrm{H}, \mathrm{Ar}-\mathrm{H}), 7.32(\mathrm{~d}, 2 \mathrm{H}, J=8.3 \mathrm{~Hz}$, $\mathrm{Ar}-\mathrm{H}), 3.95\left(\mathrm{~s}, 3 \mathrm{H},-\mathrm{COOCH}_{3}\right), 0.30\left(\mathrm{~s}, 9 \mathrm{H},-\mathrm{Si}\left(\mathrm{CH}_{3}\right)_{3}\right) ;{ }^{13} \mathrm{C} \mathrm{NMR}$ : 167.1, 164.7, 151.1, 144.9, 138, 132.2, 130.3, 130.1, 128.6, 127.2, 122.3, 52.3, 92.8, 0.0; Elemental analysis $\mathrm{C}_{26} \mathrm{H}_{24} \mathrm{O}_{4} \mathrm{Si}$ requires $\mathrm{C}, 72.87 ; \mathrm{H}$, 5.64; found C, 72.92; $\mathrm{H}, 5.71$. 
4'-[Tetradecyloxy-1,1'-\{biphenyl-4-yl 4-(trimethylsilyl)\}ethynyl] benzoate (5d)

4'-[Tetradecyloxy-1,1'-\{biphenyl-4-yl 4-(trimethylsilyl)\}ethynyl]benzoate (5d) off white solid, $0.145 \mathrm{~g}$, 59\%; IR: 2922, 2160, 1741, 1741, 1456, 1232, $840 \mathrm{~cm}^{-1}$; ${ }^{1} \mathrm{H}$ NMR: $8.13(\mathrm{~m}, 2 \mathrm{H}, \mathrm{Ar}-\mathrm{H}), 7.77-7.25$ $(\mathrm{m}, 8 \mathrm{H}, \mathrm{Ar}-\mathrm{H}), 6.92(\mathrm{~d}, 2 \mathrm{H}, J=8.8 \mathrm{~Hz}, \mathrm{Ar}-\mathrm{H}), 4.01(\mathrm{t}, 2 \mathrm{H}, J=6.6 \mathrm{~Hz}$, $\left.-\mathrm{OCH}_{2}-\right), 1.93-1.26\left(\mathrm{~m}, 24 \mathrm{H},-\mathrm{CH}_{2}-\right), 0.93\left(\mathrm{t}, 3 \mathrm{H}, J=7.5 \mathrm{~Hz},-\mathrm{CH}_{3}\right)$, $0.30\left(\mathrm{~s}, 9 \mathrm{H},-\mathrm{Si}\left(\mathrm{CH}_{3}\right)_{3}\right) ;{ }^{13} \mathrm{C}$ NMR: $132.2,132.0,129.9,128.1,127.7$, 121.8, 114.8, 31.9, 29.6, 29.6, 29.4, 29.3, 26, 22.7, 14.1, 0.0; Elemental analysis $\mathrm{C}_{38} \mathrm{H}_{50} \mathrm{O}_{3} \mathrm{Si}$ requires $\mathrm{C}, 78.30 ; \mathrm{H}, 8.65$; found $\mathrm{C}, 78.41 ; \mathrm{H}$, 8.73 .

\section{4-[4-Pentyloxy\{phenoxy-carbonyl-phenyl 4-(trimethylsilyl)\}}

ethynyl]benzoate $(\mathbf{5 e})$

4-[4-Pentyloxy\{phenoxy-carbonyl-phenyl 4-(trimethylsilyl)\} ethynyl]benzoate (5e) off white solid, 0.137 g, 65\%; IR: 2924, 2852, 2158, 1741, 1600, 1510, 1460, 1288, 1058, $885 \mathrm{~cm}^{-1}$; ${ }^{1} \mathrm{H}$ NMR: 8.21 (d, $2 \mathrm{H}, J=8.4 \mathrm{~Hz}, \mathrm{Ar}-\mathrm{H}), 8.14(\mathrm{~d}, 2 \mathrm{H}, J=8.3 \mathrm{~Hz}, \mathrm{Ar}-\mathrm{H}), 7.63(\mathrm{~d}, 2 \mathrm{H}$, $J=8.4 \mathrm{~Hz}, \mathrm{Ar}-\mathrm{H}), 7.37(\mathrm{~d}, 2 \mathrm{H}, J=8.3 \mathrm{~Hz}, \mathrm{Ar}-\mathrm{H}), 7.13(\mathrm{~d}, 2 \mathrm{H}$, $J=8.3 \mathrm{~Hz}, \mathrm{Ar}-\mathrm{H}), 6.92(\mathrm{~d}, 2 \mathrm{H}, J=8.2 \mathrm{~Hz}, \mathrm{Ar}-\mathrm{H}), 3.98(\mathrm{t}, 2 \mathrm{H}$, $\left.J=6.5 \mathrm{~Hz},-\mathrm{OCH}_{2}-\right), 1.85-1.32\left(\mathrm{~m}, 6 \mathrm{H},-\mathrm{CH}_{2}-\right), 0.93(\mathrm{t}, 3 \mathrm{H}, J=7.5$, $\left.-\mathrm{CH}_{3}\right), 0.30\left(\mathrm{~s}, 9 \mathrm{H},-\mathrm{Si}\left(\mathrm{CH}_{3}\right)_{3}\right) ;{ }^{13} \mathrm{C} \mathrm{NMR}: 164,156.9,154.9,144.1$, 132.1, 131.8, 130, 128.8, 128.5, 127.4, 122.3, 121.9, 115.1, 103.8, 98.7, $68.4,28.9,28.2,22.4,14,0.0$; Elemental analysis $\mathrm{C}_{30} \mathrm{H}_{32} \mathrm{O}_{5} \mathrm{Si}$ requires C, 71.97; H, 6.44; found C, 72.08; H, 6.48.

\section{4-[4-Cyanophenoxy-carbonyl\{phenyl 4-(trimethylsilyl)\}ethynyl] benzoate $(\mathbf{5} \boldsymbol{f})$}

4-[4-Cyanophenoxy-carbonyl\{phenyl 4-(trimethylsilyl)\}ethynyl]benzoate (5f) off white solid, 0.126 g, 68\%; IR: 2922, 2854, 2231, 2162, 1743, 1599, 1462, 1259, 1060, $756 \mathrm{~cm}^{-1} ;{ }^{1} \mathrm{H}$ NMR: 8.12 (d, 2H, $J=8.6 \mathrm{~Hz}, \mathrm{Ar}-\mathrm{H}), 7.95$ (d, 2H, $J=8.5 \mathrm{~Hz}, \mathrm{Ar}-\mathrm{H}), 7.63-7.44$ (dd, $4 \mathrm{H}$, $J=8.4 \& 8.6 \mathrm{~Hz}, \mathrm{Ar}-\mathrm{H}), 7.22(\mathrm{~m}, 4 \mathrm{H}, \mathrm{Ar}-\mathrm{H}), 0.30\left(\mathrm{~s}, 9 \mathrm{H},-\mathrm{Si}\left(\mathrm{CH}_{3}\right)_{3}\right)$; Elemental analysis $\mathrm{C}_{26} \mathrm{H}_{21} \mathrm{NO}_{4} \mathrm{Si}$ requires $\mathrm{C}, 71.05 ; \mathrm{H}, 4.82 ; \mathrm{N}, 3.19$; found $\mathrm{C}, 71.13 ; \mathrm{H}, 4.94 ; \mathrm{N}, 2.27$.

\section{4-[Nitrophenyl 3-methyl-4-\{4-(trimethylsilyl)ethynyl\}benzoyl-oxy]} benzoate (5g)

4-[Nitrophenyl 3-methyl-4-\{4-(trimethylsilyl)ethynyl\}benzoyloxy]benzoate (5g) off white solid, 0.114 g, 57\%; IR: 2924, 2852, 2162, 1743, 1521, 1456, 1350, 1259, 1163, 1060, $860 \mathrm{~cm}^{-1}$; ${ }^{1} \mathrm{H}$ NMR: 8.33-8.15 (m, 6H, Ar-H), 7.63-7.37 (m, 5H, Ar-H), 2.48 (s, 3H, $\left.\mathrm{Ar}-\mathrm{CH}_{3}\right), 0.30\left(\mathrm{~s}, 9 \mathrm{H},-\mathrm{Si}\left(\mathrm{CH}_{3}\right)_{3}\right)$; Elemental analysis $\mathrm{C}_{26} \mathrm{H}_{23} \mathrm{NO}_{6} \mathrm{Si}$ requires $\mathrm{C}, 65.94 ; \mathrm{H}, 4.90 ; \mathrm{N}, 2.96$; found $\mathrm{C}, 65.99 ; \mathrm{H}, 5.04 ; \mathrm{N}, 3.16$.

\section{4-[4'-\{3,7-Dimethyloctyloxy-phenoxy-carbonyl-phenyl- 4- \\ (trimethylsilyl)\}ethynyl-benzoate (5h)}

4-[4'-\{3,7-Dimethyloctyloxy-phenoxy-carbonyl-phenyl- 4-(trimethylsilyl)\}ethynyl-benzoate (5h) off white solid, $0.127 \mathrm{~g}$, 53\%; IR: 2924, 2852, 2160, 1737, 1600, 1506, 1456, 1267, 1190, 1066, $839 \mathrm{~cm}^{-1}$; ${ }^{1} \mathrm{H}$ NMR: $8.33-8.27$ (dd, $4 \mathrm{H}, J=8.8 \mathrm{~Hz} \& 8.2 \mathrm{~Hz}, \mathrm{Ar}-\mathrm{H}$ ), $7.62(\mathrm{~d}, 2 \mathrm{H}, J=8.5 \mathrm{~Hz}, \mathrm{Ar}-\mathrm{H}), 7.35$ (d, 2H, $J=8.4 \mathrm{~Hz}, \mathrm{Ar}-\mathrm{H}), 7.13$ (d, $2 \mathrm{H}, J=8.6 \mathrm{~Hz}, \mathrm{Ar}-\mathrm{H}), 6.97(\mathrm{~d}, 2 \mathrm{H}, J=8.2 \mathrm{~Hz}, \mathrm{Ar}-\mathrm{H}), 4.01(\mathrm{t}, 2 \mathrm{H}$, $\left.J=6.5 \mathrm{~Hz},-\mathrm{OCH}_{2}-\right), 1.83-1.24\left(\mathrm{~m}, 10 \mathrm{H},-\mathrm{CH}_{2}-\right), 0.93(\mathrm{t}, 9 \mathrm{H}$, $\left.J=6.5 \mathrm{~Hz},-\mathrm{CH}_{3}\right), 0.30\left(\mathrm{~s}, 9 \mathrm{H},-\mathrm{Si}\left(\mathrm{CH}_{3}\right)_{3}\right)$; Elemental analysis $\mathrm{C}_{35} \mathrm{H}_{42} \mathrm{O}_{5} \mathrm{Si}$ requires $\mathrm{C}, 73.65 ; \mathrm{H}, 7.42$; found $\mathrm{C}, 73.71 ; \mathrm{H}, 7.47$.

Octan-2-yl 4-[4'-\{4-(trimethylsilyl)ethynyl\}benzoyl-oxy-benzoyloxy]benzoate $(5 i)$

Octan-2-yl 4-[4'-\{4-(trimethylsilyl)ethynyl\}benzoyl-oxy-benzoyl-oxy]benzoate (5i) off white solid, 0.137 g, 57\%; IR: 2926, 2854, 2158, 1735, 1602, 1456, 1267, 1062, $844 \mathrm{~cm}^{-1}$; ${ }^{1} \mathrm{H}$ NMR: 8.30-8.12 $(\mathrm{dd}, 2 \mathrm{H}, J=8.6 \mathrm{~Hz} \& 8.4 \mathrm{~Hz}, \mathrm{Ar}-\mathrm{H}), 7.65(\mathrm{~d}, 2 \mathrm{H}, J=8.7 \mathrm{~Hz}, \mathrm{Ar}-\mathrm{H})$, 7.43-7.24 (dd, $4 \mathrm{H}, J=8.7 \mathrm{~Hz} \& 8.4 \mathrm{~Hz}, \mathrm{Ar}-\mathrm{H}), 5.14(\mathrm{~m}, 4 \mathrm{H}$, $\left.-\mathrm{COOCH}-\mathrm{CH}_{3}-\right), 1.83-1.21\left(\mathrm{~m}, 10 \mathrm{H},-\mathrm{CH}_{2}-\right), 0.91(\mathrm{t}, 3 \mathrm{H}, \mathrm{J}=6.5 \mathrm{~Hz}$,
$\left.-\mathrm{CH}_{3}\right), 0.30\left(\mathrm{~s}, 9 \mathrm{H},-\mathrm{Si}\left(\mathrm{CH}_{3}\right)_{3}\right)$; Elemental analysis $\mathrm{C}_{34} \mathrm{H}_{38} \mathrm{O}_{6} \mathrm{Si}$ requires C, 71.55; $\mathrm{H}, 6.71$; found $\mathrm{C}, 71.62 ; \mathrm{H}, 6.80$.

\section{4-[4'-Hexadecyloxy-phenoxy-carbonyl \{phenyl4-(trimethylsilyl)\} ethynyl)benzoate (5j) \\ 4-[4'-Hexadecyloxy-phenoxy-carbonyl\{phenyl4-(trime-} thylsilyl)\}ethynyl)benzoate (5j) off white solid, $0.144 \mathrm{~g}, 52 \%$; IR: 2922, 2852, 2158, 1735, 1604, 1508, 1454, 1251, 1053, $842 \mathrm{~cm}^{-1} ;{ }^{1} \mathrm{H}$ NMR: 8.12-8.05 (dd, $2 \mathrm{H}, J=8.6 \mathrm{~Hz} \& 8.4 \mathrm{~Hz}, \mathrm{Ar}-\mathrm{H}), 7.63-7.45(\mathrm{~m}$, $4 \mathrm{H}, \mathrm{Ar}-\mathrm{H}), 7.12(\mathrm{~d}, 2 \mathrm{H}, J=8.5 \mathrm{~Hz}, \mathrm{Ar}-\mathrm{H}), 6.95(\mathrm{~d}, 2 \mathrm{H}, J=8.4 \mathrm{~Hz}$, $\mathrm{Ar}-\mathrm{H}), 3.93\left(\mathrm{t}, 2 \mathrm{H}, J=6.5 \mathrm{~Hz},-\mathrm{OCH}_{2}-\right), 1.84-1.25\left(\mathrm{~m}, 28 \mathrm{H},-\mathrm{CH}_{2}-\right)$, $0.92\left(\mathrm{t}, 3 \mathrm{H}, J=7.6 \mathrm{~Hz},-\mathrm{CH}_{3}\right), 0.30\left(\mathrm{~s}, 9 \mathrm{H},-\mathrm{Si}\left(\mathrm{CH}_{3}\right)_{3}\right)$; Elemental analysis $\mathrm{C}_{41} \mathrm{H}_{54} \mathrm{O}_{5} \mathrm{Si}$ requires $\mathrm{C}, 75.19 ; \mathrm{H}, 8.31$; found $\mathrm{C}, 75.24 ; \mathrm{H}$, 8.39 .

\section{4-[3-Methyl-4'-octadecyloxy-phenoxy-carbonyl-phenyl-4- trimethylsilyl)-ethynyl]-benzoate (5k)}

4-[3-Methyl-4'-octadecyloxy-phenoxy-carbonyl-phenyl-4-trimethylsilyl)-ethynyl]-benzoate (5k off white solid, 0.168 g, 56\%; IR: 2920, 2850, 2160, 1737, 1600, 1506, 1456, 1271, 1172, 1016, $839 \mathrm{~cm}^{-1}$; ${ }^{1} \mathrm{H}$ NMR: 8.13 (d, $\left.2 \mathrm{H}, J=8.8 \mathrm{~Hz}, \mathrm{Ar}-\mathrm{H}\right), 7.75(\mathrm{~d}, 2 \mathrm{H}, J=8.7 \mathrm{~Hz}$, $\mathrm{Ar}-\mathrm{H}), 7.65(\mathrm{~s}, 1 \mathrm{H}, \mathrm{Ar}-\mathrm{H}), 7.54(\mathrm{~d}, 2 \mathrm{H}, J=8.6 \mathrm{~Hz}, \mathrm{Ar}-\mathrm{H}), 7.12(\mathrm{~d}, 2 \mathrm{H}$, $J=8.7 \mathrm{~Hz}, \mathrm{Ar}-\mathrm{H}), 6.74(\mathrm{~d}, 2 \mathrm{H}, J=8.4 \mathrm{~Hz}, \mathrm{Ar}-\mathrm{H}), 4.01(\mathrm{t}, 2 \mathrm{H}$, $\left.J=6.6 \mathrm{~Hz},-\mathrm{OCH}_{2}-\right), 3.83\left(\mathrm{~s}, 3 \mathrm{H},-\mathrm{OCH}_{3}\right), 1.82-1.15\left(\mathrm{~m}, 32 \mathrm{H},-\mathrm{CH}_{2}-\right)$, $0.92\left(\mathrm{t}, 3 \mathrm{H}, J=7.5 \mathrm{~Hz}-\mathrm{CH}_{3}\right), 0.30\left(\mathrm{~s}, 9 \mathrm{H},-\mathrm{Si}\left(\mathrm{CH}_{3}\right)_{3}\right) ;{ }^{13} \mathrm{C}$ NMR: 165, 164.6, 153.5, 149.2, 148.8, 148.3, 132.2, 130.1, 129, 128.7, 124.6, 122.9, 122.7, 121.5, 112.9, 111, 104, 98.5, 69.3, 56.3, 32.1, 29.8, 29.7, 29.5, 29.1, 26, 22.8, 14.2, 0.0; Elemental analysis $\mathrm{C}_{44} \mathrm{H}_{60} \mathrm{O}_{6} \mathrm{Si}$ requires $\mathrm{C}$, 74.12; $\mathrm{H}, 8.48$; found $\mathrm{C}, 74.17 ; \mathrm{H}, 8.50$.

\section{4-[Benzyloxy\{phenyl 4-(trimethylsilyl)\}ethynyl]benzoate (5I)}

4-[Benzyloxy\{phenyl 4-(trimethylsilyl)\}ethynyl]benzoate (51) off white solid, $0.158 \mathrm{~g}$, 72\%; IR: 2924, 2852, 2158, 1732, 1506, 1456 1246, 1014, $763 \mathrm{~cm}^{-1}$; ${ }^{1} \mathrm{H}$ NMR: 7.97 (d, $\left.2 \mathrm{H}, J=8.8 \mathrm{~Hz}, \mathrm{Ar}-\mathrm{H}\right)$, $7.43-7.37(\mathrm{~m}, 5 \mathrm{H}, \mathrm{Ar}-\mathrm{H}), 6.93-6.85(\mathrm{dd}, 6 \mathrm{H}, J=8.6 \mathrm{~Hz} \& 8.7 \mathrm{~Hz}$, $\mathrm{Ar}-\mathrm{H}), 4.96\left(\mathrm{~s}, 2 \mathrm{H},-\mathrm{OCH}_{2} \mathrm{Ph}\right), 0.30\left(\mathrm{~s}, 9 \mathrm{H},-\mathrm{Si}\left(\mathrm{CH}_{3}\right)_{3}\right)$; Elemental analysis $\mathrm{C}_{32} \mathrm{H}_{28} \mathrm{O}_{5} \mathrm{Si}$ requires $\mathrm{C}, 73.82 ; \mathrm{H}, 5.42$; found $\mathrm{C}, 73.90 ; \mathrm{H}$, 5.48 .

Benzyl 4-[4'-\{(trimethylsilyl)ethynyl-benzoyl $\}$ oxy]benzoate (5m)

Benzyl 4-[4'-\{(trimethylsilyl)ethynyl-benzoyl\}oxy]benzoate (5m) off white solid, 0.124 g, 69\%; IR: 2922, 2854, 2158, 1737, 1707, 1602, 1454, 1377, 1271, 1251, $1072 \mathrm{~cm}^{-1}$; ${ }^{1} \mathrm{H}$ NMR: $8.23(\mathrm{~m}, 5 \mathrm{H}$, $\mathrm{Ar}-\mathrm{H}), 7.62-7.36(\mathrm{~m}, 8 \mathrm{H}, \mathrm{Ar}-\mathrm{H}), 5.36\left(\mathrm{~s}, 2 \mathrm{H}, \mathrm{Ar}-\mathrm{COO}-\mathrm{CH}_{2}-\right), 0.30$ (s, $\left.9 \mathrm{H},-\mathrm{Si}\left(\mathrm{CH}_{3}\right)_{3}\right)$; Elemental analysis $\mathrm{C}_{26} \mathrm{H}_{24} \mathrm{O}_{4} \mathrm{Si}$ requires $\mathrm{C}, 72.87$; $\mathrm{H}, 5.64$; found $\mathrm{C}, 72.96$; $\mathrm{H}, 5.70$.

\section{4-[4-\{Nitrophenyl-diazenyl-phenyl 4-(trimethylsilyl)ethynyl\}]} benzoate (5n)

4-[4-\{Nitrophenyl-diazenyl-phenyl 4-(trimethylsilyl)ethynyl\}] benzoate (5n) orange coloured solid, 0.115 g, 61\%; IR: 2922, 2854, 2152, 1732, 1599, 1529, 1456, 1346, 1203, 1055, $842 \mathrm{~cm}^{-1}$; ${ }^{1} \mathrm{H}$ NMR: $8.23(\mathrm{~m}, 5 \mathrm{H}, \mathrm{Ar}-\mathrm{H}), 7.65-7.34(\mathrm{~m}, 8 \mathrm{H}, \mathrm{Ar}-\mathrm{H}), 5.35(\mathrm{~s}, 2 \mathrm{H}$, $\left.\mathrm{Ar}-\mathrm{COO}-\mathrm{CH}_{2^{-}}\right), \quad 0.30$ (s, 9H, -Si( $\left.\left(\mathrm{CH}_{3}\right)_{3}\right)$; ESI-MS: 443.8 Da; Elemental analysis $\mathrm{C}_{26} \mathrm{H}_{24} \mathrm{O}_{4} \mathrm{Si}$ requires $\mathrm{C}, 72.87 ; \mathrm{H}, 5.64$; found $\mathrm{C}$, 72.96; H, 5.70.

\section{4-[4-\{Pentylphenyl-diazenyl-phenyl 4-(trimethylsilyl)ethynyl\}] benzoate (5o)}

4-[4-\{Pentylphenyl-diazenyl-phenyl 4-(trimethylsilyl)ethynyl\}] benzoate (5o) orange coloured solid, 0.145 g, 73\%; IR: 2926, 2854 2156, 1732, 1456, 1375, 1273, 1080, $840 \mathrm{~cm}^{-1}$; ${ }^{1} \mathrm{H}$ NMR: 8.23 (m, 5H, $\mathrm{Ar}-\mathrm{H}$ ), 7.63-7.34 (m, 8H, Ar-H), 5.33 (s, 2H, Ar-COO- $\left.\mathrm{CH}_{2}-\right), 0.30$ $\left(\mathrm{s}, 9 \mathrm{H},-\mathrm{Si}\left(\mathrm{CH}_{3}\right)_{3}\right)$; Elemental analysis $\mathrm{C}_{26} \mathrm{H}_{24} \mathrm{O}_{4} \mathrm{Si}$ requires $\mathrm{C}, 72.87$; $\mathrm{H}, 5.64$; found $\mathrm{C}, 72.96$; $\mathrm{H}, 5.70$. 


\section{Acknowledgements}

Grateful thanks are due to the University Grants Commission, Government of India, New Delhi for financial assistance: Grant F. No. 36-42/2008 (SR). The authors are thankful to Dr. D. Vijayaraghavan for recording NMR spectra, Mrs. K. N. Vasudha for recording thermal analysis and the Indian Institute of Science, Bangalore for mass spectral analysis.

\section{Appendix A. Supplementary data}

Supplementary data related to this article can be found at http:// dx.doi.org/10.1016/j.jorganchem.2014.09.037.

\section{References}

[1] J.L. Serrano, Metallomesogens: Synthesis, Properties and Applications, Whiley-VCH, 1996.

[2] G. Hennrich, P.D. Ortiz, E. Cavero, R.E. Hanes, J.L. Serrano, Eur. J. Org. Chem. (2008) 4575-4579.

[3] W. Wan, W.J. Guang, K.Q. Zhao, W.Z. Zheng, L.F. Zhang, J. Organomet. Chem. 557 (1998) 157-161.

[4] D.M. Walba, Adv. Synth. React. Solids 1 (1991) 173-235.

[5] M. Hird, Liq. Cryst. 38 (2011) 1467-1493.

[6] S.A. Hudson, P.M. Maitlis, Chem. Rev. 93 (1993) 861-885.

[7] T. Kaharu, H. Matsubara, S. Takahashi, J. Mater. Chem. 2 (1992) 43-47.

[8] C.T. Liao, Z.L. Wu, N.C. Wu, J.Y. Liu, M.H. Jiang, S.F. Zou, J.Y. Lee, Mol. Cryst. Liq. Cryst. 533 (2010) 3-15.

[9] T. Ganicz, T. Pakula, W.A. Stanczyk, J. Organomet. Chem. 691 (2006) $5052-5055$.
[10] E.B. Florjanczyk, J.T. Soltysiak, J. Organomet. Chem. 695 (2010) 1911-1917.

[11] T. Hanasaki, Y. Kamei, K. Mandai, K. Uno, K. Kaneko, Liq. Cryst. 38 (2011) $841-848$.

[12] J. Lu, M. Tian, Q. Chen, J. Wen, Liq. Cryst. 18 (1995) 101-103.

[13] G.W. Skelton, D. Dong, R.P. Tuffin, S.M. Kelly, J. Mater. Chem. 13 (2003) 450-457.

[14] I.G. Shenouda, L.C. Chien, Macromolecules 26 (1993) 5020-5023.

[15] C.R. Gopalkrishnan, B.K. Sadashiva, Macromol. Rapid. Commun. 19 (1998) 97-102.

[16] H.T. Srinivasa, S. Hariprasad, Org. Chem. Ind. J. 8 (2012) 130-134.

[17] H.T. Srinivasa, S. Hariprasad, Mol. Cryst. Liq. Cryst. 588 (2014) 17-27.

[18] B.S. Palakshamurthy, H.C. Devarajegowda, H.T. Srinivasa, S. Sreenivasa, Vijithkumar, Acta Cryst. E69 (2013) o621-0622.

[19] C. Eaborn, A.R. Thompson, D.R.M. Walton, J. Chem. Soc. (Sec. C) 15 (1967) 1364-1366.

[20] M. Katono, T. Bessho, M. Wielopolski, M. Marszalek, J.E. Moser, R.H. Baker, S.M. Zakeeruddin, M. Gratzel, J. Phys. Chem. C 116 (2012) 16876.

[21] R. Murashige, Y. Hayashi, S. Ohmori, A. Torii, Y. Aizu, Y. Muto, Y. Murai, Y. Oda, M. Hashimoto, Tetrahedron 67 (2011) 641-649.

[22] K.M. Mahadevan, H.N. Harish Kumar, M.N. Jagadeesh, H.T. Srinivasa, Mol. Cryst. Liq. Cryst. 570 (2013) 20-35.

[23] D. Ziobro, R. Dabrowski, M. Tykarska, W. Drzewinski, M. Filipowicz, W. Rejmer, K. Kusmierek, P. Morawiak, W. Piecek, Liq. Cryst. 39 (2012) 1011-1032.

[24] G. Shanker, M. Prehm, C. Tschierske, J. Mater. Chem. 22 (2012) 168-174.

[25] M.L. Rahman, G. Hegde, M.M. Yusoff, M.N.F.A. Malek, H.T. Srinivasa, S. Kumar, New. J. Chem. 37 (2013) 2460-2467.

[26] J.W. Goodby, Angew. Chem. Int. Ed. Engl. 47 (2008) 2754-2787.

[27] Z.Q. Yu, C.Z. Zhu, Z. Zhang, J.H. Liu, J.W.Y. Lam, B.Z. Tang, Chin. Chem. Lett. 22 (2011) 1355-1358.

[28] J. Zhao, K. Tatani, Y. Ozaki, Appl. Spectrosc. 59 (2005) 620-629.

[29] A. Kellera, S.Z.D. Cheng, Polymer 39 (1998) 4461-4487. 